\title{
Geographic Information System Mapping Potential of E-Market in Pandemic Period
}

\section{Sistem Informasi Geografis Pemetaan Potensi E-Market pada Masa Pandemi}

\author{
Elda Anzeli Hasibuan1); Surya Darma 2); Nurbaiti2) \\ 1,2) Program Studi Manajemen, Fakultas Ekonomi dan Bisnis Islam, Universitas Islam Negeri Sumatera Utara \\ Email: ${ }^{1)}$ eldaanjelyhasibuan@gmail.com; ${ }^{2)}$ sryadarma06@gmail.com; ${ }^{2)}$ nurbaiti@uinsu.ac.id
}

How to Cite :

Hasibuan, E. A., Darma, S., Nurbaiti. (2022). Geographic Information System Mapping Potential of E-Market in Pandemic Period. Jurnal Ekonomi Manajemen Akuntansi Dan Keuangan, 3(1). DOI: https://doi.org/10.53697/emak.v3i1

ARTICLE HISTORY

Received [22 Desember 2021]

Revised [29 Desember 2021]

Accepted [05 Januari 2022]

\section{KEYWORDS}

Geographic Information

System, Mapping Potential, E-

Market,

Pandemic Period

This is an open access article under the $C C-B Y$-SA license

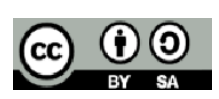

\section{ABSTRAK}

Perubahan pola pikir masyarakat dalam memperoleh informasi yang akurat dipengaruhi oleh kemajuan teknologi informasi yang semakin cepat. Saat ini, salah satu aplikasi teknologi yang paling luas adalah di bidang pemetaan. Teknologi pemetaan banyak digunakan untuk menyederhanakan berbagai tugas penting. Teknologi pemetaan yang paling banyak digunakan saat ini adalah sistem informasi geografis. Sistem Informasi Geografis (SIG) adalah tren teknologi pemetaan dalam bentuk sistem informasi terkomputerisasi yang dirancang untuk bekerja dengan referensi spasial. Di masa pandemi saat ini, transaksi jual beli produk yang ditawarkan sulit dilakukan karena pembatasan interaksi sosial antar masyarakat, sehingga menyulitkan UKM untuk menjual produknya. Perkembangan teknologi informasi khususnya internet tentunya dapat dijadikan sebagai media untuk mengatasi permasalahan tersebut. Adanya sistem informasi berbasis website dimaksudkan untuk mendukung pemasaran khususnya dalam memberikan informasi produk dan harga yang detail kepada konsumen. Kehadiran pandemi COVID-19 telah mengubah dunia dengan berbagai tantangan yang belum pernah terjadi sebelumnya dan berdampak sangat besar terhadap aktivitas manusia sehari-hari, sehingga mengakibatkan memburuknya perekonomian global. Pandemi COVID-19 saat ini memasuki tahun kedua yang mengharuskan aktivitas sehari-hari dilakukan dari rumah. Munculnya pandemi COVID-19 juga menyebabkan para pemilik usaha merasakan penurunan yang sangat nyata. Dalam kondisi seperti itu, diperlukan sistem informasi komunikatif berbasis web, yang darinya diharapkan pemecahan masalah khususnya penyediaan informasi tentang produk unggulan UKM.

\section{ABSTRACT}

Changes in people's mindsets in obtaining accurate information are influenced by the rapid advancement of information technology. Currently, one of the most widespread applications of technology is in the field of mapping. Mapping technology is widely used to simplify important tasks. The most widely used mapping technology today is geographic information systems. Geographic Information System (GIS) is a mapping technology trend in the form of computerized information systems designed to work with spatial references. In the current pandemic period, buying and selling 
products offered are difficult to carry out due to restrictions on social interaction between communities, making it difficult for SMEs to sell their products. The development of information technology, especially the internet, can certainly be used as a medium to overcome these problems. The existence of a website-based information system is intended to support marketing, especially in providing detailed product and price information to consumers. The presence of the COVID-19 pandemic has changed the world with unprecedented challenges and has had a huge impact on daily human activities, resulting in a worsening of the global economy. The COVID-19 pandemic is currently entering its second year, requiring daily activities to be carried out from home. The emergence of the COVID-19 pandemic has also caused business owners to feel a very real decline. In such conditions, a web-based communicative information system is needed, from which it is hoped that problem solving, especially the provision of information about the superior products of SMEs, is needed.

\section{PENDAHULUAN}

Teknologi Sistem Informasi Geografis (SIG) mengalami perkembangan cepat. SIG dibentuk dengan memanfaatkan informasi yang didapatkan dengan mengolah data dalam jumlah besar, yaitu data geografis atau data tentang posisi suatu objek di permukaan bumi. Saat ini, teknologi SIG menggabungkan operasi pemrosesan data umum berdasarkan database, seperti menangkap visualisasi unik dan berbagai manfaat yang dapat ditawarkan oleh analisis geografis melalui gambar peta. SIG dapat ditampilkan dalam wujud aplikasi berbasis web atau aplikasi desktop. Selain itu, SIG juga dapat menjelaskan mengenai suatu peristiwa, perencanaan strategis, dan mempermudah dalam analisis masalah umum misalnya bidang ekonomi, kependudukan, sosial, pertahanan, dan pariwisata. SIG memiliki kemampuan baik untuk memvisualisasikan data spasial seperti perubahan bentuk, warna, ikon, dan ukuran. Hal ini dimaksudkan untuk memudahkan masyarakat dalam mengakses informasi mengenai letak geografis suatu daerah.

\section{LANDASAN TEORI}

\section{Pengertian Sistem Informasi Geografis (SIG)}

Sistem Informasi Geografis berasal dari gabungan 3 kata: Sistem, Informasi, dan Geografis. Dari ketiganya, dapat dipahami bahwa Sistem Informasi Geografis adalah penggunaan sistem berisi informasi mengenai kondisi Bumi dalam sudut pandang keruangan.

Sobat, sebelumnya apakah kalian sudah pernah mempelajari penginderaan jauh? Penginderaan jauh dan Sistem Informasi Geografis (SIG) tidak bisa dipisahkan. SIG merupakan sistem khusus untuk mengolah data base yang berisi data referensi geografis dan memiliki informasi spasial.

Masukan data SIG banyak diperoleh dari citra penginderaan jauh. Semua informasi itu diproses dengan menggunakan komputer yang kemudian dapat dikombinasikan menjadi informasi yang diinginkan. Jadi singkatnya, SIG merupakan sistem yang berfungsi untuk mengumpulkan, mengelola, menyimpan, dan menyajikan segala data yang berkaitan dengan kondisi geografis suatu wilayah.

\section{Electronic Market (e-market)}

E-market merupakan salah satu cara dalam memasarkan hasil atau produk berbasis teknologi informasi dan komunikasi, dengan e-market dapat memperpendek mata rantai bisnis serta memperluas akses informasi dan pasar. Menurut Kotler (2004:74) e-market adalah sisi pemasaran dari e-commerce, yang terdiri dari kerja dari perusahaan untuk mengkomunikasikan sesuatu, mempromosikan, dan menjual barang dan jasa melalui internet. 


\section{METODE PENELITIAN}

Penelitian ini dilaksanakan guna mendeskripsikan kekuatan e-commerce pada masa pandemi. Dalam penelitian ini, analisis difokuskan pada lima kategori e-commerce utama di Indonesia, seperti Shopee, Tokopedia, Buka Lapak, Lazada, dan Blibli. Dalam melaksanakan penelitian ini, terdapat tahapan sebelum tujuan akhir antara lain:

Pengumpulan dan pemrosesan data situs web e-niaga. Dalam penelitian ini, data yang dikumpulkan mencakup jumlah pengunjung situs web, pengunjung bulanan, pengunjung unik, halaman yang dikunjungi per kunjungan, rasio pentalan, kunjungan rata-rata, dan lalu lintas pencarian. Data-data tersebut diperoleh dari riset internet yang ada di platform analisis web bernama SimilarWeb, yang terintegrasi dengan Google Analytics. Data tersebut akan diproses oleh platform akan menempati tingkatan tertinggi dalam e-commerce dalam hal kinerja situs web pasar. Kemudian dari data-data tersebut, website total visitor, monthly visitor, search traffic, unique visitor, dan bounce rate akan menjadi data utama yang dianaliis dengan software Tableau.

Pengumpulan dan pengolahan data e-commerce berdasarkan persepsi konsumen. Dalam penelitian ini, pendataan e-commerce yang paling sering digunakan oleh konsumen berdasarkan persepsi konsumen dilakukan dengan cara menyebarkan angket. Setelah mempersiapkan angket, angket tersebut dibagikan kepada 150 konsumen dalam jangka waktu kurang dari satu bulan. Untuk mencapai target 150 responden, pendistribusian dilaksanakan dengan memanfaatkan berbagai media sosial seperti Facebook dan Instagram. Selain itu, peneliti menggunakan media komunikasi online misalnya WhatsApp dan Line untuk menyebarkan angket sesuai target. Kemudian data dari 150 responden menjadi data terpenting yang dikompilasi dengan Ms. Excel.

\section{HASIL DAN PEMBAHASAN}

Saat ini, Internet atau World Wide Web (WWW) telah memberikan pengaruh terhadap perilaku pasar bisnis, industri dan perusahaan. Berbagai instansi mengalami perubahan untuk memenuhi tuntutan bisnis dan teknologi. Tl sekarang digunakan untuk mendorong aktivitas bisnis dan pasar. Internet telah menjadi sistem komunikasi utama dan berperan dalam peningkatan bisnis dan transaksi. Hal tersebut telah menyebabkan perubahan signifikan dalam bisnis.

Internet memberikan peluang untuk bidang penjualan di pasar konsumen atau konsumen di pasar industri. Penjualan langsung barang dan jasa (direct selling) melalui internet dikenal sebagai perdagangan elektronik. Dinamika model bisnis e-commerce setiap tahun meningkat pesat dengan penyempurnaan perkembangan ICT dan teknologi informasi, menawarkan berbagai peluang untuk model bisnis baru untuk tumbuh. Perkembangan e-market juga memberikan pengaruh dalam struktur industri. E-market telah merevolusi cara berbisnis, seperti toko buku dan agen perjalanan, melakukan transaksi. Secara umum, perusahaan besar dapat memanfaatkan skala ekonomi dan memberikan penawaran harga yang lebih rendah.

Berdasarkan penelitian yang dilakukan didapatkan hasil yaitu Pameran e-commerce di Indonesia, salah satu dari 20 perusahaan e-commerce terbesar Juli 2020, meliputi Shopee, Tokopedia, Buka Lapak, Lazada, Blibli, JD.ID, Orami, Bhinneka, Zalora, Sociolla, Matahari, Blanja.com, Elevenia, Fabelio, Jakmall, Laku6, Mapemall, Monotaro.id, Ralali dan Mothercare. Ke-20 situs ecommerce ini diurutkan menurut performa website, yang dipecah menjadi beberapa performa, yaitu Monthly Visitor, Page Per Visit, Bounce Rate, Total Visitor, Individual visitors, Average visitors, dan Search Traffic. Setelah itu, 20 data ecommerce di atas diolah dengan software Tableau untuk menampilkan performa dari 20 website platform ecommerce tersebut. Analisis dengan perangkat lunak Tableau ini bertujuan untuk mengidentifikasi 5 e-commerce paling besar dari 20 e-commerce pertama yang dijelaskan di Indonesia. Selain itu, analisis ini bertujuan untuk memvisualisasikan data urutan e-commerce agar lebih mudah dipahami dan diinterpretasikan. 


\section{KESIMPULAN DAN SARAN}

System e bussines pada masa pandemi ini sangat mengalami kemajuan yang cukup tinggi dikarenakan semua masyarakat lebih banyak memilih untuk memenuhi kebutuhannya dengan berbelanja online tanpa harus berpergian untuk mendapatkan apa yang mereka inginkan. Dan dengan begitu juga dapat membantu masyarakat yang terkena dampak akan covid 19 ini pada usaha nya. Sehingga usahanya bisa tetap berjalan dengan menggunakan media social.

\section{DAFTAR PUSTAKA}

Assauri, Sofjan. 2014. Manajemen pemasaran. Jakarta: Rajawali Press.

Prahasta, Eddy. 2002. Konsep-konsep dasar Sistem Informasi Geografis, Informatika, Bandung.

Baum, David, 1999, E-comemerce, Jakarta, Gramedia Pustaka Utama

Bakos, J. Y. (1991), A strategic analysis of electronic marketplaces. MIS quarterly, 295-310.

Chaffey, D., \& Smith, P. R. (2013). Emarketing Exellence. Planning and optimizing your digital marketing. Abingdon: Routledge.

Chiang dan Dolakia. (2003), "Factors Driving Consumer Intention To Shop Online: An Empirical Investigation," Journal of Consumer Psychology, Vol. 13, No. 1-2, pp. 177-18 